\title{
Damage identification of RC bridge decks under fatigue loading
}

\section{Detección de daño estructural de losas de hormigón armado de puentes sometidas a fatiga}

\author{
C. Zanuy $^{(*)}$, L. F. Maya-Duque ${ }^{(*)}$, J. M. Gallego ${ }^{(*)}$, P. de la Fuente ${ }^{(*)}$
}

\begin{abstract}
The complex nature of structural phenomena still requires the comparison between numerical models and the real structural performance. Accordingly, many civil structures are monitored to detect structural damage and provide updated data for numerical models. Monitoring usually relies on the change of dynamic properties (experimental modal analysis). Regarding concrete structures, existing works have typically focused on the progressive decrease of natural frequencies under gradually increasing loads. In this paper, high-cycle fatigue effects are analyzed. An experimental campaign on specimens reproducing the top slab of concrete girders has been carried out, including fatigue tests and a reference static test. Impact-excitation tests were done at different stages to extract dynamic properties. Output-only models (only based on the structural response to an external excitation that is not measured) were used as identification techniques. The evolution of dynamic properties was correlated with damage development, with emphasis on the fatigue process stages: crack formation, cyclic reduction of tension-stiffening and brittle fracture of the reinforcement.
\end{abstract}

Keywords: Concrete bridges; fatigue; cracking; damage identification; output-only models.

\section{RESUMEN}

La naturaleza compleja de muchos fenómenos estructurales requiere que los modelos numéricos necesiten ser verificados con el comportamiento estructural real. Por ello, muchas estructuras son monitorizadas, tanto para detectar posibles daños estructurales como para proporcionar datos a incluir en los modelos. A menudo, la monitorización se basa en el cambio de las propiedades dinámicas mediante técnicas de análisis modal experimental. Con respecto al hormigón estructural, la mayoría de los trabajos existentes se ha centrado en el cambio de las frecuencias propias con cargas monótonamente crecientes. En este artículo se analizan los efectos de la fatiga. Se ha llevado a cabo una campaña experimental sobre piezas que reproducen la losa superior de tableros de puentes, realizándose ensayos de fatiga y uno estático de referencia. Las propiedades dinámicas se han ido extrayendo mediante técnicas de output-only a partir de ensayos de excitación mediante impacto. El cambio de las propiedades dinámicas se ha correlacionado con las etapas del proceso de fatiga: formación de fisuras, reducción de tension-stiffening y rotura frágil de la armadura.

Palabras clave: Puentes de hormigón; fatiga; fisuración; identificación del daño; modelos output-only.

(*) ETS Ingenieros de Caminos - Universidad Politécnica de Madrid, (España).

${ }^{(* *)}$ Department of Research and Development, Cementos Argos, Medellin (Colombia).

Persona de contacto/Corresponding author: czs@caminos.upm.es (C. Zanuy)

Cómo citar este artículo/Citation: Zanuy, C., Maya-Duque, L. F., Gallego, J. M., de la Fuente, P. (2014). Damage identification of RC bridge decks under fatigue loading. Informes de la Construcción, 66(EXTRA-1): mo04, doi: http://dx.doi.org/10.3989/ic.13.087.

Licencia / License: Salvo indicación contraria, todos los contenidos de la edición electrónica de Informes de la Construcción se distribuyen bajo una licencia de uso y distribución Creative Commons Reconocimiento no Comercial 3.o. España (cc-by-nc). 


\section{INTRODUCTION}

Experimental modal analysis provides a wide field of applications to detect structural damage of concrete structures. Such techniques focus on the evaluation of structural dynamic properties (natural frequencies, modal shapes and damping factors) and the relationship between their evolution and the change of structural parameters (stiffness, mass or boundary conditions). A significant number of modal identification techniques has been developed in the last years and a good survey was reported by Cunha and Caetano (1). Modal identification techniques can be classified into two categories: input-output techniques and output-only techniques. While in input-output techniques the excitation is measured and frequency response functions (FRF) can be therefore derived, output-only techniques are only based on the dynamic response, remaining the excitation source as unknown (2). For civil engineering structures, where external sophisticated equipment would be needed to excite a wide band of frequencies and simultaneously measure the input signal, output-only techniques have shown to be very appropriate to extract dynamic properties. In addition, output-only techniques can take advantage of the ambient excitation due to wind or traffic loads (ambient vibration testing, AVT), which avoids the interruption of the in-service performance of the structure. Many civil structures have been tested under such conditions -e.g. (3),(4)-. In addition, operational modal analysis provides realistic parameters to asses the capabilities of numerical models (5).

Dynamic identification techniques offer an interesting way to assess damage of concrete structures. Due to the availability of instrumentation systems, non destructive vibration monitoring of civil structures has rapidly increased for the last years. Many monitoring activities related to concrete structures rely on the measurement of the change of dynamic properties. Reinforced concrete has a highly nonlinear behaviour, whose response is not always easy to be determined in advance under a combination of loads (6). Cracking is the most usual damaging process that affects such response. Since cracking leads to a reduction of stiffness, it has an influence on dynamic properties. Some researchers have experimentally shown the relationship between progressive cracking and change of natural frequencies and damping ratios (7). However, cracking can be in turn due to diverse external solicitations: monotonic increasing loads, time-dependent effects, repeated loading, corrosion-induced cover cracking, etc. Other damaging sources that affect dynamic properties of concrete structures are yielding of the reinforcement, loss of tension stiffening, settlement of foundations or corrosion of the reinforcement (8). The potential of experimental modal analysis could be also advantageous to determine the possibilities of repairing techniques after a structure has been locally damaged (9). In order to develop efficient monitoring techniques for reinforced concrete, a fundamental study on the evolution of damage due to different loading processes has to be firstly established (10). Particular experimental works are needed to identify the implications of different damaging sources and derive conclusions about the correlation between change of dynamic properties and structural damage. So far, most of the experimental studies regarding reinforced concrete have dealt with the evolution of cracking due to gradually increasing loads (11).

An increasing attention has been paid to the effect of repeated loading on concrete structures for the last years. In bridges, traffic loads are of repetitive nature and they can lead to local fatigue damage (12) (13) (14). It is well known that repeated loads lead to progressive cracking and tension stiffening reduction. Furthermore, fatigue fracture of the reinforcement may take place in the high-cycle domain. Premature damage detection of concrete bridges is of large significance and dynamic identification techniques may provide a helpful tool. To do it, the study of correlation between change of dynamic properties and different damage stages due to repeated loading is necessary. In this paper, the evolution of dynamic properties of specimens reproducing the top slab of boxgirder concrete bridges is studied. The analysis focuses on the transverse fatigue behaviour of the bridge, which is more susceptible to be damaged than the longitudinal direction in medium- and long-span bridges due to the presence of longitudinal prestressing. Since dynamic properties of concrete structures are load-dependent, mainly due to concrete material nonlinearities (15) (16), different excitation techniques or dynamic identification models may lead to different values of the dynamic properties, especially damping (11). In order to account for this fact and avoid uncertainties, the testing procedure and the identification techniques used here are defined before the presentation of experimental results.

\section{EXPERIMENTAL PROGRAM}

\subsection{Overview of tests}

The analysis developed in this paper focuses on the evolution of dynamic properties of reinforced concrete bridge decks. The experimental results obtained in the tests performed in (17) are used here. A brief summary of such tests is described in this section. The dynamic excitation tests, the results regarding the dynamic properties and the subsequent analysis are reported in the following sections of this paper. The tests were designed to study the transverse fatigue behaviour of box-girder concrete bridges. The specimens represented at $1 / 2$ scale the top slab and the webs until the point of zero transverse moment of a typical railway viaduct of the Spanish network with a span length of $40 \mathrm{~m}$ (17) (18). The specimens were symmetrically loaded at the free edges of the lateral cantilevers and they were supported on cylindrical steel rollers of $6 \mathrm{~cm}$ diameter. A discussion regarding the relation between the test configuration and the real situation of bridges can be found in (17). One reference specimen was loaded to static failure and two specimens were subjected to fatigue loading. The test configuration, specimen geometry and reinforcement lay-out can be observed in Figure 1. The main data of the three tests are given in Table 1 . The reinforcement consisted of hot-rolled deformed bars of quality B500SD, with characteristic yield and ultimate strength of 500 and 575 $\mathrm{MPa}$, respectively, according to the Spanish code for structural concrete (19).

The static test ST1 was used as reference for the fatigue tests. It showed ductile flexural failure. The maximum applied load during the stage of yielding of the reinforcement was $86.18 \mathrm{kN}$. The load-midspan deflection curve is plotted in Figure 2a. Due to the small reinforcement ratio ( $\rho=0.53 \%$ at the central region of the specimen and $\rho=0.34 \%$ at the clamped edge of the cantilevers), the member exhibited a significant tension stiffening capacity. Before yielding, the cracks mainly developed at the central region of the specimen (top side). After yielding, the lateral cantilevers also cracked -refer to (17)-. The first cracking load was $30.1 \mathrm{kN}$ and the yielding load was $67.0 \mathrm{kN}$. 


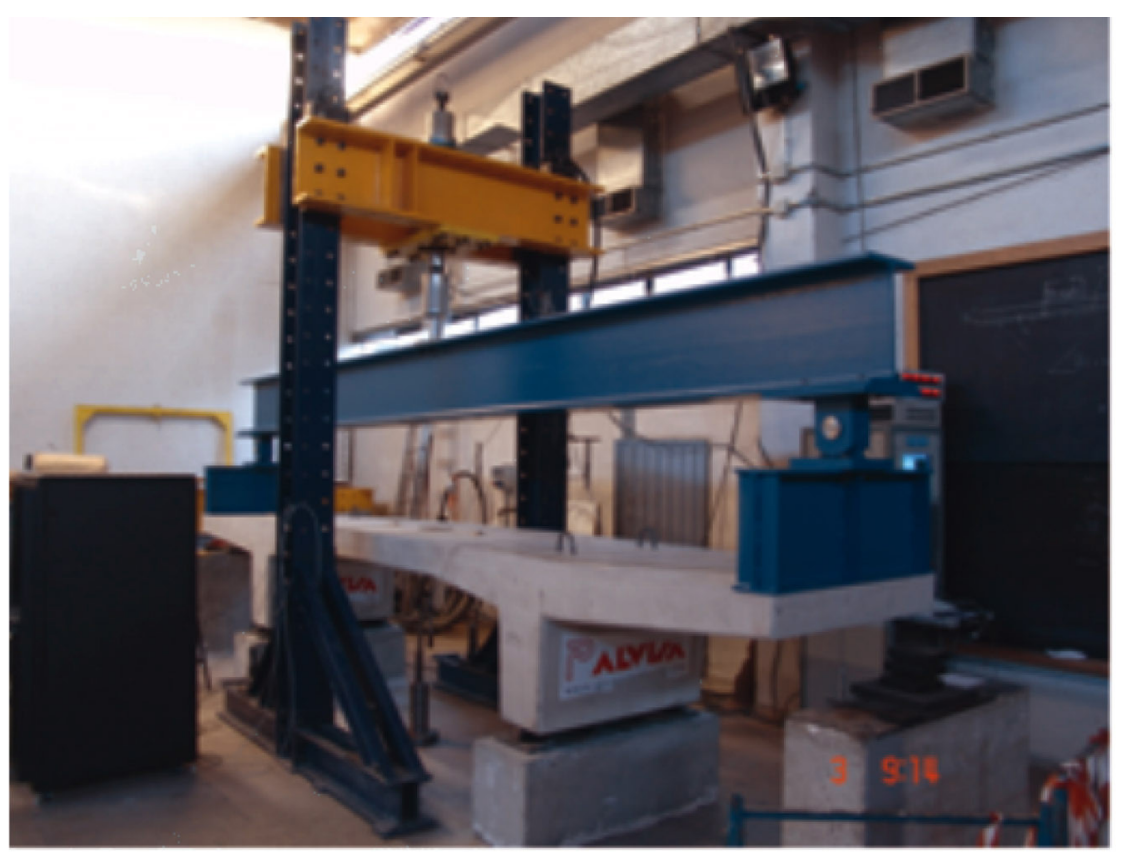

(a)
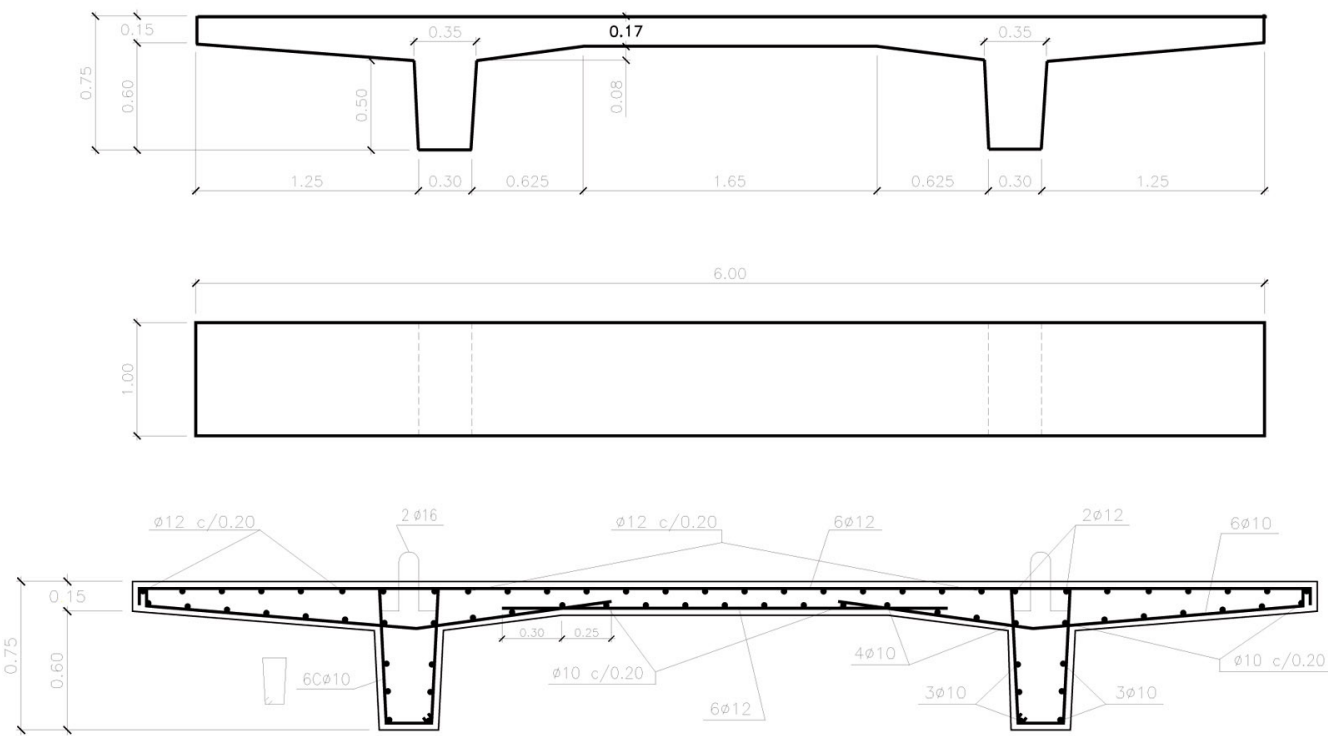

(b)

Figure 1. (a) View of the test configuration, and (b) specimen geometry and reinforcement (17).

Both fatigue tests (FT1 and FT2) developed three stages: 1) crack formation, 2) stabilized cracking, and 3) fatigue failure. The first stage corresponded to the formation of flexural cracks in the specimens. For test FT1, the last crack formation was registered at load cycle 330000, while for test FT2, where the maximum load was larger, no further cracks formed after load cycle 300. During the second stage, existing cracks wid- ened with number of cycles and no additional cracks formed, indicating the cycle-dependent reduction of tension stiffening contribution. The third stage corresponded to the brittle fatigue fracture of the tensile reinforcement in the central region of the specimens. The instant of fatigue failure was detected by the sudden increase of deflections and deformations. Three broken bars were detected in each fatigue test af-

Table 1. Main parameters of the tests: load values, concrete properties at the age of testing and number of cycles to fatigue fracture.

\begin{tabular}{|c|c|c|c|c|c|c|c|c|c|}
\hline Test & Type & $\begin{array}{c}\text { Applied load } \\
(\mathbf{k N})\end{array}$ & $\begin{array}{c}\text { Frequency } \\
(\mathbf{H z})\end{array}$ & $\begin{array}{c}\boldsymbol{f}_{\mathbf{c}} \\
(\mathbf{M P a})\end{array}$ & $\begin{array}{c}\boldsymbol{E}_{\mathrm{c}} \\
(\mathbf{M P a})\end{array}$ & $\begin{array}{c}\boldsymbol{f}_{\text {ct }} \\
(\mathbf{M P a})\end{array}$ & $\begin{array}{c}\mathbf{1}^{\text {st }} \mathbf{b a r} \\
\text { fracture }\end{array}$ & $\begin{array}{c}\mathbf{2}^{\text {nd }} \mathbf{b a r} \\
\text { fracture }\end{array}$ & $\begin{array}{c}\mathbf{3}^{\text {rd }} \mathbf{b a r} \\
\text { fracture }\end{array}$ \\
\hline ST1 & Static & 86.18 & - & 48.1 & 36870 & 3.90 & - & - & - \\
\hline FT1 & Fatigue & $10-40$ & 2.0 & 46.5 & 35177 & 3.59 & 2993677 & 3038877 & 3102433 \\
\hline FT2 & Fatigue & $10-50^{*}$ & 1.0 & 51.8 & 36258 & 4.70 & 523339 & 526339 & 528181 \\
\hline
\end{tabular}

* In the first load cycle of test FT2, the maximum load was $60 \mathrm{kN}$ 
ter they were finished. Cracks developed on the top side of the central region of the specimens, remaining the lateral cantilevers almost uncracked. The three typical stages can be observed through the evolution of measured deflections, plotted in Figure 2b-c. The maximum deflection corresponding to the first cycle $(N=1)$ is indicated with a black point in the graphics in order to note the significant deflection increase undergone in the crack formation stage. The structural damage developed in the two first stages was due to progressive cracking and loss of tension stiffening contribution. Concrete-related fatigue typically develops a three-stage process similar to the one plotted in Fig. 2b-c -(20)-. However, it must be noted that in the present tests, failure was due to fatigue of the rein-

(a)

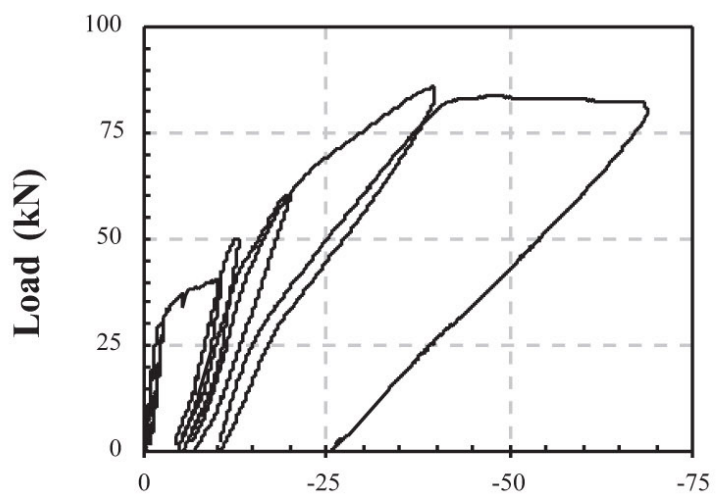

Midspan Deflection (mm)

(b)

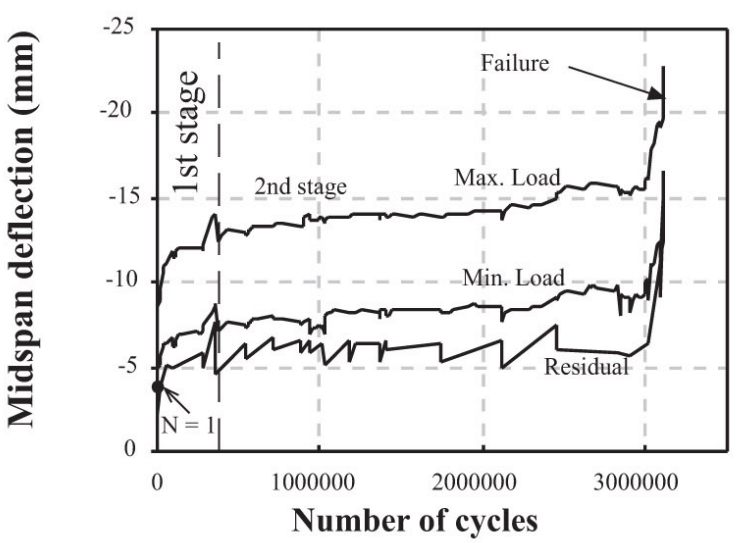

(c)

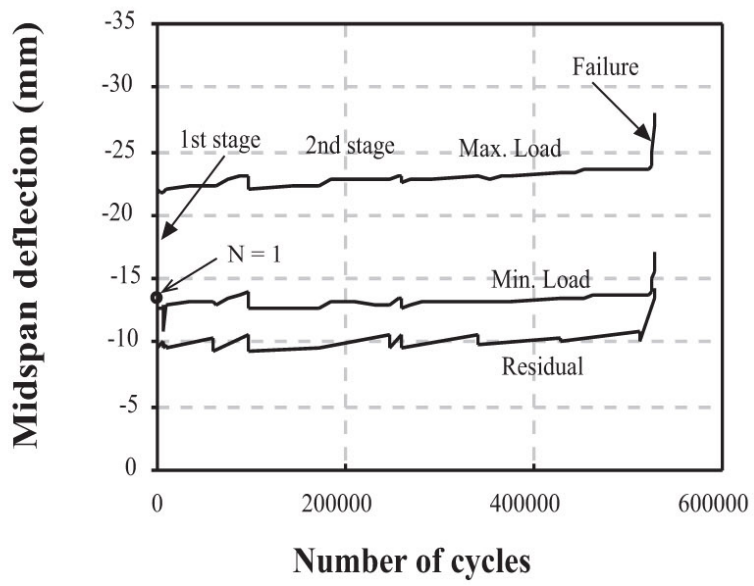

Figure 2. (a) Load-midspan deflection of test ST1; (b) Evolution of midspan deflection of test FT1; (c) Evolution of midspan deflection of test FT2. forcement and, therefore, the third stage does not correspond to the third stage of concrete fatigue processes. Accordingly, there is no relationship between the failure instant and the slope of the deflection evolution measured during the second stage. It is noted that lightly reinforced concrete members have a large tension stiffening capacity (21), and the present tests indicate that repeated loads significantly decrease this contribution, leading to the cyclic increase of cracks and deflections. Therefore, it deserves to be studied whether the effect of repeated loads on the serviceability of reinforced concrete can be detected and explained by the evolution of dynamic properties. In that case, experimental modal techniques could be use to monitor structures susceptible to this damaging source. In addition, another interesting damage to be detected is the fatigue fracture of the reinforcing bars. The correlation of this effect with the change of dynamic properties has not been studied so far, to the authors' knowledge.

\subsection{Dynamic testing}

To determine the evolution of dynamic properties, impact excitation vibration tests were conducted at relevant instants of the experiments summarized in the previous section. The specimens were excited by the impact of a $3 \mathrm{~kg}$ steel ball dropped from a height of $0.50 \mathrm{~m}$. The ball impacted on the top side of the specimens at the midpoint, as plotted in Figure 3 . This procedure mainly excites longitudinal symmetric modes (it is noted that longitudinal modes of the specimen refer to transverse modes of the bridge). The height of $0.50 \mathrm{~m}$ was fitted before the tests so that the response of the first impact was fully dissipated before the second impact of the ball took place. This guaranteed that the isolated effect of a single impact could be used in the analysis. Before the application of the impacts the specimens were unloaded, the load application equipment was switched off, and the auxiliary loading frame was removed. The support conditions were the same as the ones referred to in the previous section (steel rollers over $0.43 \times 0.38 \times 1.00 \mathrm{~m}$ concrete bricks).

The sequence of preparation and execution of dynamic tests is represented in Figure 4. Four impacts were given at each testing stage. Four piezo-resistive accelerometers (B\&K 4573) with sensitivity $67 \mathrm{mV} / \mathrm{g}$ were used to register the dynamic response. The accelerometers were located on the top side of the specimens (Figure 3). A more refined mesh was used to identify the modal shapes with more accuracy, as explained later. The input excitation due to the impact of the drop weight was not measured. Therefore, output-only
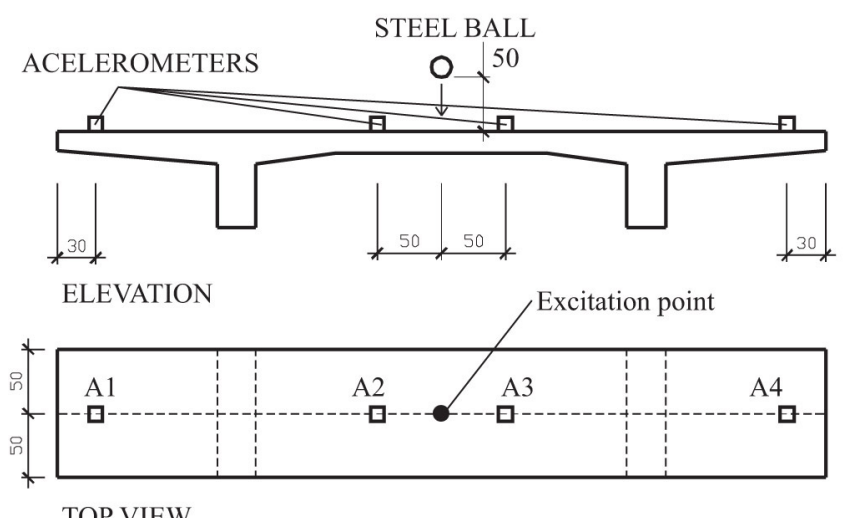

TOP VIEW

Figure 3. Configuration of the impact excitation tests (dimensions in $\mathrm{cm}$ ). 
modal identification techniques from the free damped vibration response are to be used to estimate dynamic parameters. Accelerations were measured with an HBM MGC-plus data acquisition system. The sampling rate of the digital recorder was $2400 \mathrm{~Hz}$, which was enough to study the evolution of frequencies below $750 \mathrm{~Hz}$. A Butterworth low-pass filter with a filter frequency of $1000 \mathrm{~Hz}$ was used in the data acquisition. A typical acceleration record is plotted in Figure 5. It can be observed that the vibration is the result of a single impact. It is noted that all the experiments were performed in a laboratory environment without temperature or moisture changes, which avoided that environmental factors affect dynamic properties.

In the static experiment (ST1), the dynamic tests were conducted after each load stage. The load stages consisted of a loading phase, followed by 60 seconds during which the load was held constant, and a subsequent complete unloading. The loading and unloading rate was $0.5 \mathrm{kN} / \mathrm{s}$. The maximum load level of each load stage was progressively increased $(5 \mathrm{kN}, 10 \mathrm{kN}, 20 \mathrm{kN}, 30 \mathrm{kN}, 40 \mathrm{kN}, 50 \mathrm{kN}, 60 \mathrm{kN}$ and failure), which means that the structural damage was progressively introduced in the specimen, according to the stages observed in Figure 2a: uncracked state until $30.1 \mathrm{kN}$, cracking stage between 30.1 and $67.0 \mathrm{kN}$, and yielding of the reinforcement thereafter.

In the fatigue tests (FT1 and FT2), the configuration and procedure to develop the impact excitation tests was the same as in the static test. The impacts were applied at relevant number of load cycles, in order to obtain the evolution of dynamic properties in a logarithmic scale. This included, at least, the following number of load cycles: $N=0$ (undamaged state, before the application of any load), 1, 10, 100, 1000, 10000, 50000,100000 , and thereafter every 180000 cycles for test FT1 and 70000 cycles for test FT2.

\section{ESTIMATION OF DYNAMIC PROPERTIES}

\subsection{Identification methods}

In this section, the data processing techniques employed to determine dynamic properties are summarized. Due to the test configuration, output-only identification techniques were used to identify the natural frequencies, modal shapes and damping ratios. The free damped vibration responses measured with the accelerometers (see the example plotted in Figure 5) were transformed in the frequency domain

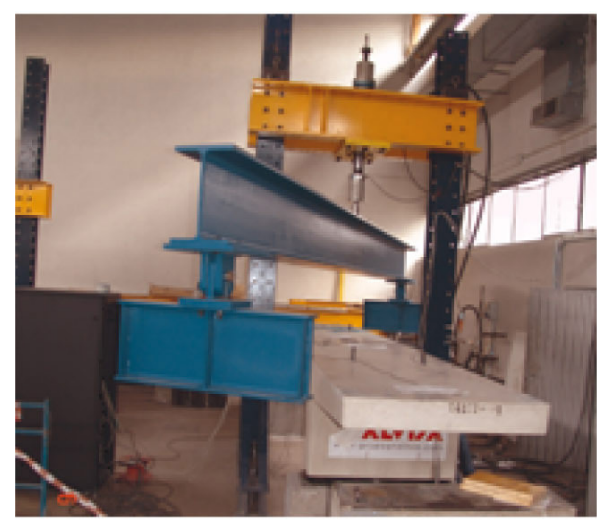

(a)

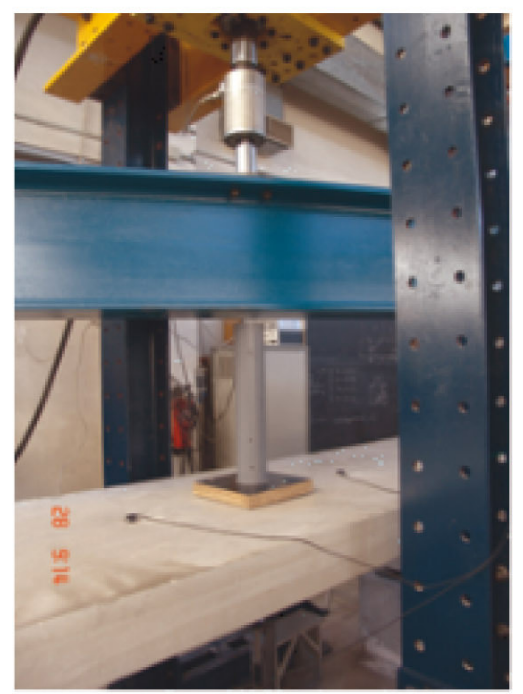

(c)

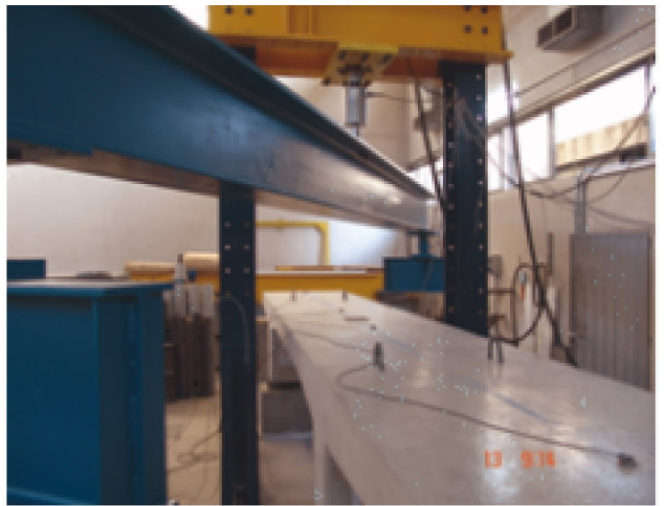

(b)

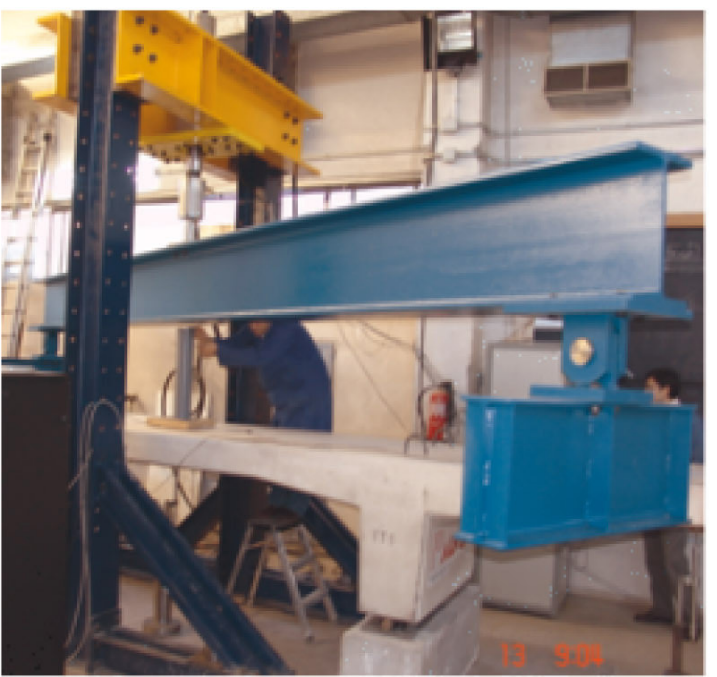

(d)

Figure 4. Sequence of impact excitation tests: (a) remove of auxiliary spread beam after switching off the load application equipment; (b) the auxiliary beam is suspended freely from the actuator; (c) collocation of the PVC tube to guide the steel ball; (d) dropping the steel ball. 


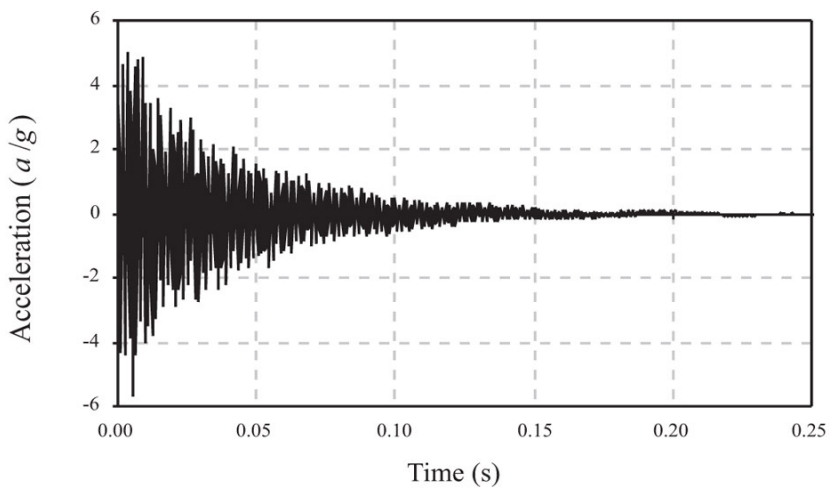

Figure 5. Typical acceleration record in an impact test.

to study the damage development. No techniques based on the time domain analysis have been employed in this paper. A short summary of the fundamentals of the identification methods used is given in the following paragraphs.

Natural frequencies have been firstly estimated by the peak picking method from the average normalized power spectral densities (ANPSD). This method was conveniently implemented by Felber (22) and its simplicity has made it very attractive for structural applications (23). It is based on the identification of natural frequencies as the peaks of the ANPSDs. The power spectral density (PSD) has to be first obtained for each individual acceleration signal measured in the time domain (Figure 5), as follows:

$$
G_{i i}(\Omega)=A_{i}^{*}(\Omega) A_{i}(\Omega)
$$

where $G_{i i}(\Omega)$ is the PSD of the acceleration at point $i, A_{i}(\Omega)$ is the Fourier transform of the acceleration at point $i$, and $A^{*}{ }_{i}(\Omega)$ is the complex conjugate of $A_{i}(\Omega)$. The PSD is therefore the square of the magnitude of the Fourier transform of the acceleration. The ANPSD is computed for each sensor by normalizing and then averaging the four impacts given at each testing stage.

The employ of the four accelerometers plotted in Figure 3 allows to estimate natural frequencies and their evolution. However, it is not accurate enough to identify the modal shape corresponding to each frequency. A more refined mesh is necessary to plot the modal shapes with better resolution and therefore compare the experimental shapes with numerical results. In this paper the potential modal ratio (PMR) functions proposed by Felber (22) have been used. Within the field of output-only identification techniques, the PMRs are used instead FRFs and they represent the relationship between the Fourier transform of a roving signal and a fixed reference signal. The amplitude of the PMRs at the natural frequencies represents the coordinate of the modal shape that corresponds to that frequency in the location of the roving sensor. The higher the number of roving signals, the better the resolution of the modal shapes. According to Felber, the PMR can be obtained as:

$$
M_{i j}(\Omega)=\left|\frac{G_{i j}(\Omega)}{G_{i i}(\Omega)}\right| P W_{i j}(\Omega) C W_{i j}(\Omega)
$$

where $i$ is the fixed sensor and $j$ is the roving sensor. $G_{i j}(\Omega)$ is the cross PSD between signals $i$ and $j, P W_{i j}$ is a phase win- dow function that eliminates values associated with phase angles not near $\mathrm{O}^{\circ}$ and $180^{\circ}$ (typically deviations smaller than $10^{\circ}$ are accepted), and $C W_{i j}$ is a coherence window that eliminates values with small coherence (normally values lower than 0.90). The PMR technique was used to identify the modal shapes in test FT2 at the undamaged state, before the application of any load. The mesh of sensor locations is represented in Figure 6. The reference accelerometer was located in point 1 , while the roving signal was subsequently located in points 2-32. The excitation was due to the impact of the steel ball on the midpoint of the top side of the specimen, as explained in section 2.2. It is noted that points $1,14,19$ and 31 correspond to the positions of the accelerometers indicated in Figure 3.

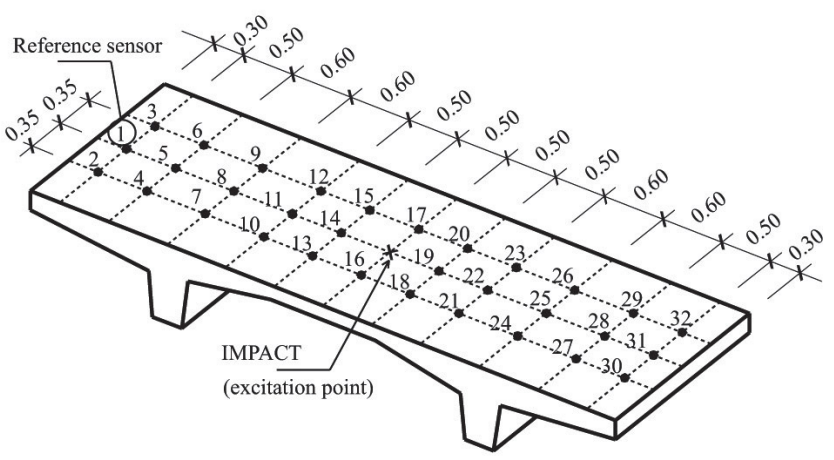

Figure 6. Sensor mesh to obtain PMRs in test FT2.

The estimation of damping ratios is usually the most difficult part of experimental modal analysis. The frequency domain decomposition (FDD) method proposed by Brincker et al. (24) has been used in this paper. This technique is based on the singular value decomposition of the PSD matrix at each frequency, as follows:

$$
G(\Omega)=U(\Omega) S(\Omega) V^{H}(\Omega)
$$

In the above equation, the spectra matrix $G(\Omega)$ that contains the PSD functions $G_{i j}(\Omega)$ is decomposed into a set of singular vectors $U(\Omega)$ and $V(\Omega)$ and the corresponding diagonal matrix $S(\Omega)$ that contains the singular values in the diagonal. The superscript $\mathrm{H}$ indicates complex conjugate matrix transpose. Under the hypotheses of white noise excitation, well separated modes and light damping, the singular value decomposition results in the following equation

$$
G(\Omega)=\Phi(\Omega) S(\Omega) \Phi^{T}(\Omega)
$$

where $\Phi(\Omega)$ contains the singular vectors and $S(\Omega)$ gives the singular values $s_{i j}(\Omega)$ of the output PSD matrix. The peaks of the singular values represent the resonance frequencies. A frequency band around each peak provides the auto PSD function of the corresponding single degree of freedom system, which can be taken back to the time domain by inverse Fourier transform. Brincker et al. indicated that the band width around the peaks of the singular values can be better selected by using the modal assurance criterion, which resulted in the enhanced FDD method -refer to (24)-. This e-FDD technique has been used in this paper. In the time domain, the damping ratio of each mode can be estimated from the logarithmic decrement $\delta$, which is calculated as the absolute value of the slope of the regression line of the logarithms of the local maxima extracted from the free decay acceleration of each isolated single degree of freedom signal. Due to the 
nonlinear behaviour of structural concrete, the estimation of the logarithmic decrement depends on the amplitude of the acceleration (16). Therefore, the result is a function of the number of maxima employed in the regression line. In order to use a uniform criterion, the damping ratio obtained in this paper was estimated from the maxima within the first 0.2 seconds of the acceleration response (the first acceleration peak was eliminated too). An example corresponding to the estimation of the undamaged damping ratio of mode $\mathrm{M}_{3}$ of test FT1 is given in Figure 7. After obtaining the logarithmic decrement, the damping ratio $\zeta$ is derived as:

$$
\zeta=\frac{\delta}{\sqrt{4 \pi^{2}+\delta^{2}}}
$$

It is noted that FDD also results in the estimation of natural frequencies by determining the number of zero-crossings of the isolated accelerations in the time domain. In the following paragraphs, this result is compared with the frequency obtained with the ANPSD.

\subsection{Determination of dynamic properties}

The experimental set up and equipment has made it possible to study of the evolution of the frequency and damping ratio of eight modes of frequency smaller than $750 \mathrm{~Hz}$. Besides such eight modes, which will be studied in detail, the PMR technique was able to obtain a total of ten modal shapes for test FT2 at the undamaged state and the results are plotted in Figure 8 . The nomenclature of the modes does not have any physical meaning.

The experimental mode shapes can be compared with the numerical results represented in Figure 9, which were obtained with the finite element software ANSYS (25). The 13 modal shapes plotted in Figure 9 have a natural frequency smaller than $750 \mathrm{~Hz}$. In the model, eight-node brick elements with three translational degrees of freedom at each node (element Solid45) were used with the following properties: $E=36258$ $\mathrm{MPa}, \mathrm{v}=0.2$, density $=2500 \mathrm{~kg} / \mathrm{m}^{3}$. The support conditions were modelled reproducing the steel rollers and the concrete blocks below them. Due to the impact excitation, mostly symmetrical modes were experimentally identified. Accordingly, the theoretically obtained modes M7, M9 and M12 could not be identified with the experimental techniques and $\mathrm{M}_{4}$ and M5 could only be detected with the PMR. The evolution of the natural frequencies and damping ratios for the other modes

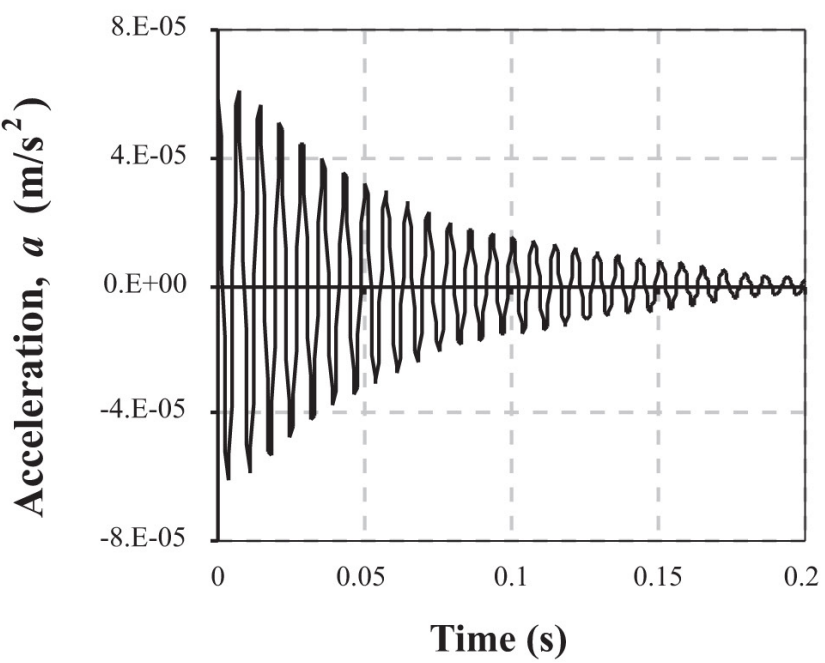

(a)

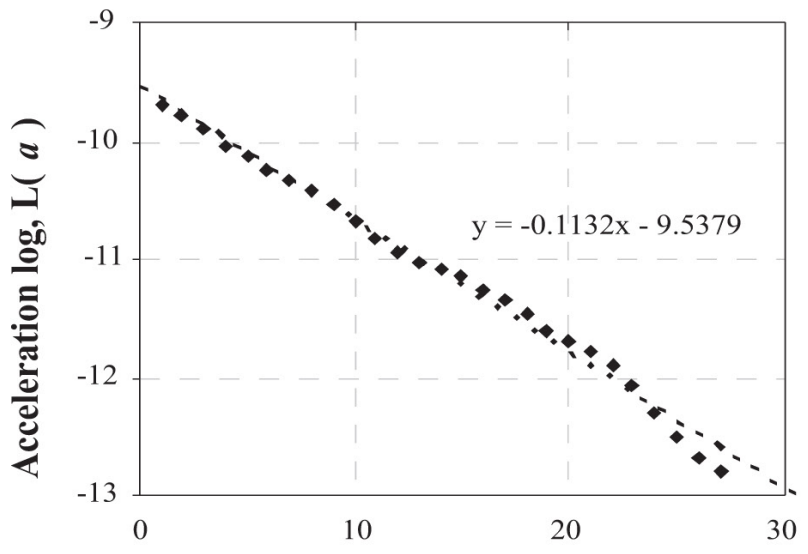

Non-dimensional time (t $\cdot f)$

(b)

Figure 7. Estimation of undamaged (before testing) damping ratio of mode M3 (test FT1): (a) Isolated single degree of freedom signal of mode M3; (b) Regression line to calculate logarithmic decrement $(\delta=0.1132)$.

could be followed with the techniques explained in the previous section. Modes M1, M3, M8 and M10 represent the first four symmetrical bending modes. Mode M5 is the same as M8 with some excitation of the supports (this modal shape is not obtained numerically if the supports are not modelled).

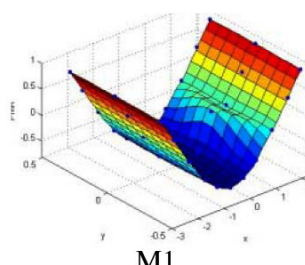

M1

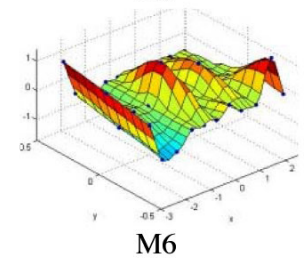

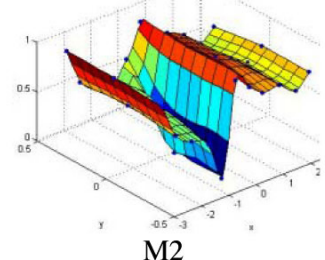

M2

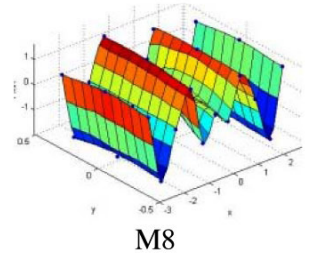

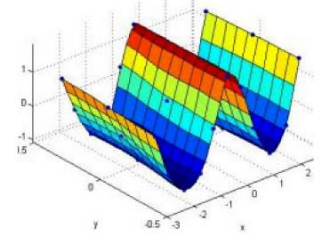

M3

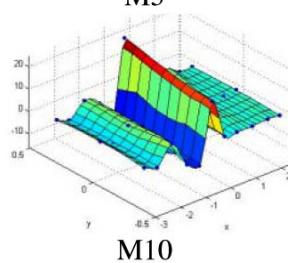

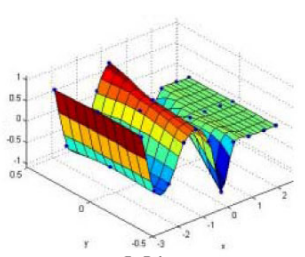

M4

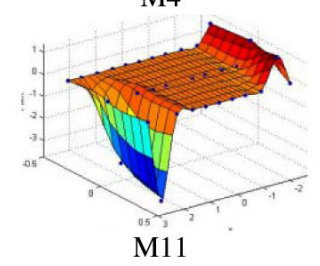

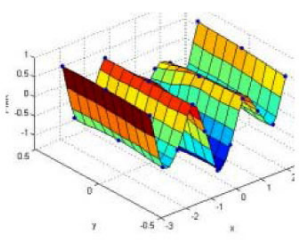

M5

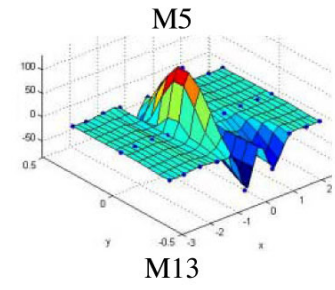

Figure 8. Experimental mode shapes obtained with PMR technique for test FT2 (undamaged state). 


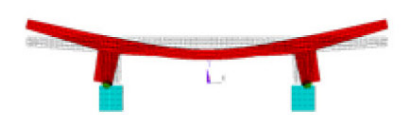

M1
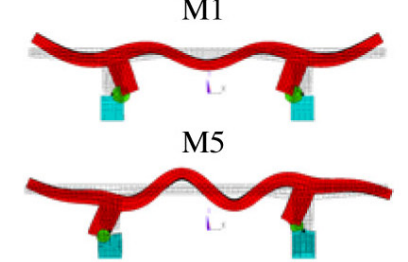

M9

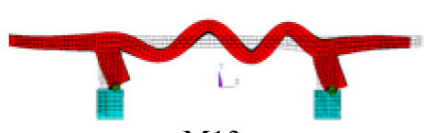

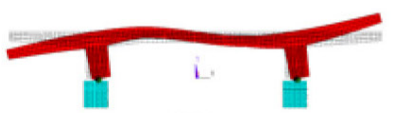

M2

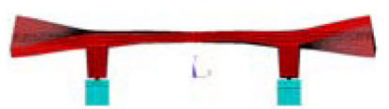

M6

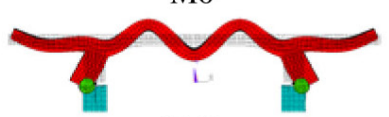

M10

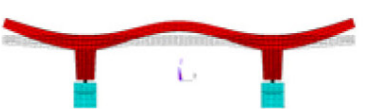

M3

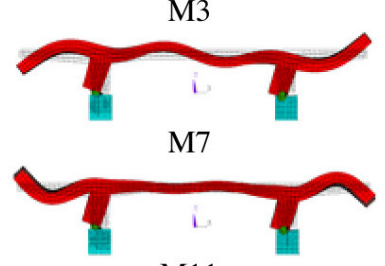

M1 1

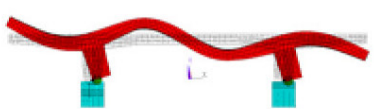

M4

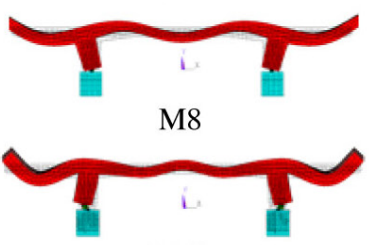

M12

M13

Figure 9. Numerical mode shapes obtained from finite element model.

Modes M2, M4, M7 and M9 are the first asymmetrical bending modes. Mode M6 represents transverse bending of the cantilevers. Modes M11 and M12 represent the asymmetrical and symmetrical bending of the cantilevers, while in mode M13 only the central region of the specimen is excited.

The natural frequencies corresponding to the undamaged state of modes M1-M3, M6, M8, M10-M11 and M13 for the three tests are listed in Table 2. In the table, the values obtained with the ANPSD and enhanced FDD (e-FDD) techniques are given. It can be observed that both techniques provide very similar values. The frequencies that correspond to the modes identified only with the PMR but not with ANPSD or e-FDD are $166.04 \mathrm{~Hz}$ (mode M4) and 191.09 Hz (mode M5). M7, M9 and M12 were not experimentally found, as already explained. The analysis of the frequency change and structural damage is performed in section 4 .

In addition to the evolution of natural frequencies, the damping ratio could be used as a damage indicator. The development of damage is indicated by an increase of the damping ratio. Table 3 shows the damping ratios of the modes studied that correspond to the undamaged state of each specimen. The evolution during the tests was in a way similar to the one used to show the frequency change. The study of the evolution with structural damage is performed in the following section.

\section{ANALYSIS OF CORRELATION BETWEEN STRUCTURAL DAMAGE AND CHANGE OF DYNAMIC PROPERTIES}

Among other objectives, the experimental campaign was intended to evaluate the correlation between the progressive damaging process of the reinforced concrete specimens and the resulting changes that can be observed in the dynamic properties. Regarding the evolution of natural frequencies, the analysis indicates a similar trend of the frequency change and the evolution of deflections during the tests plotted in Figure 2. The experimental stages indicated in section 2.1 can be observed through the frequency change experienced during the tests. According to the experimental results (17), cracking damage mainly developed at the central region of the specimens and fatigue fracture of rebars took place at the same zone. Since the change of dynamic properties can be related to the location of damage, the most appropriate modes to analyze the decrease of frequencies or increase of damping are those where damage occurs at locations of high modal curvature. Among the modes represented in Figure 8, M13 seems therefore very appropriate to analyze the experimental behaviour.

According to the above paragraph, the evolution of frequency M13 will be taken as representative of the experimental re-

Table 2. Natural frequencies at the undamaged state of tested specimens (Hz). N.D.: not detected.

\begin{tabular}{|c|c|c|c|c|c|c|c|c|}
\hline \multicolumn{8}{|c|}{ Natural frequencies obtained with ANPSD } \\
\hline Test & M1 & M2 & M3 & M6 & M8 & M10 & M11 & M13 \\
\hline ST1 & 21.97 & N.D. & 131.98 & 221.78 & 319.70 & N.D. & 487.65 & 701.88 \\
\hline FT1 & 25.26 & 52.81 & 139.16 & 232.91 & 325.34 & N.D. & 509.99 & 731.83 \\
\hline FT2 & 16.48 & 47.75 & 119.53 & 216.58 & 303.96 & 414.92 & 542.50 & 713.38 \\
\hline \multicolumn{7}{|c|}{ Natural frequencies obtained with enhanced FDD } \\
\hline Test & M1 & M2 & M3 & M6 & M8 & M10 & M11 & M13 \\
\hline ST1 & 21.98 & 50.04 & 132.13 & 222.02 & N.D. & N.D. & 487.93 & 702.24 \\
\hline FT1 & 25.19 & 49.70 & 139.15 & 233.46 & 325.14 & N.D. & 510.33 & 732.01 \\
\hline FT2 & 16.48 & 51.18 & 122.12 & N.D. & 303.21 & 381.77 & N.D. & 714.96 \\
\hline
\end{tabular}

Table 3. Damping ratios at the undamaged state of tested specimens. N.D.: not detected.

\begin{tabular}{|c|c|c|c|c|c|c|c|c|}
\hline \multicolumn{7}{|c|}{ Damping ratios obtained with enhanced FDD } \\
\hline Test & M1 & M2 & M3 & M6 & M8 & M10 & M11 & M13 \\
\hline ST1 & 0.08147 & 0.06536 & 0.01772 & 0.00922 & N.D. & N.D. & 0.00532 & 0.00451 \\
\hline FT1 & 0.08265 & 0.05582 & 0.01842 & 0.01118 & 0.00291 & N.D. & 0.00541 & 0.00389 \\
\hline FT2 & 0.10048 & 0.06920 & 0.03506 & N.D. & 0.00859 & 0.01139 & N.D. & 0.00508 \\
\hline
\end{tabular}


sponse of the static test ST1. During the first uncracked stage, there was no frequency change, which agrees with the fact that the stiffness is not reduced as long as concrete does not crack. The frequency then experienced a progressive decrease during the cracking stage. If the evolution of the frequency with the load is plotted in a way similar to the load-deflection diagram, it is observed that the frequency and the deflection follow the same evolution -refer to Figure 10(a)-. Even the crack formation and stabilized cracking stages can be distinguished by a different rate of the frequency decrease. In addition, a larger decrease of the frequency is observed in the stage of yielding of the reinforcement. The frequency change with load is found to follow the same evolution of deflections with load, which can be observed in Figure 10(b)-(c). The high coefficient of determination indicates that a linear correlation exists between the frequency reduction and the evolution of deflections. Damage due to monotonic loading can be therefore predicted with the evolution of natural frequencies, even in the stage of yielding of the reinforcement.
For the fatigue tests (FT1 and FT2), the frequency decrease was quite significant during the first crack formation stage (see the evolution of frequency M13, for example), which agrees with the increase of deflections during the tests. The damage rate stabilized during the second stage, showing a small linear decrease of the frequency with number of load cycles. Finally, a sudden jump of the frequency indicated the fatigue fracture of the reinforcement. These three stages correspond very well with the evolution of deflections and deformations with number of cycles, showing that the change of natural frequencies can be used to identify the typical fatigue behaviour of reinforced concrete. The evolution of frequency M13 with load cycles during the fatigue tests has been represented in Figure 11 and vertical lines have been added in order to distinguish the three fatigue stages. Further conclusions can be drawn if the frequency evolution developed in the static test is used as a reference to identify the stages of the fatigue tests. This is analyzed with the load-frequency diagram of the three tests plotted in Figure 12 -the graphic refers to frequency M13, similar

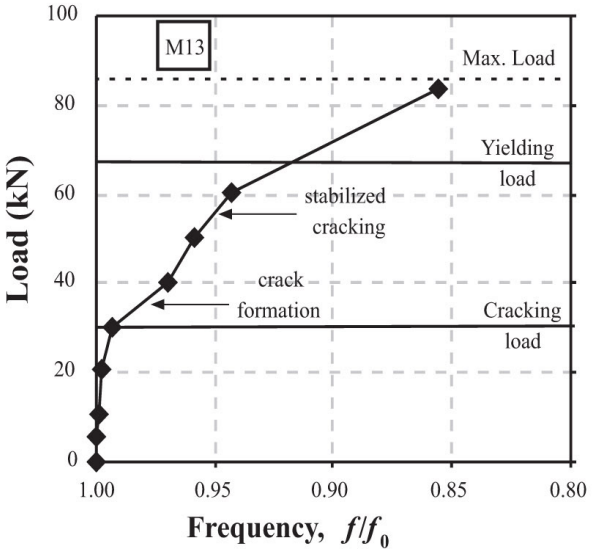

(a)

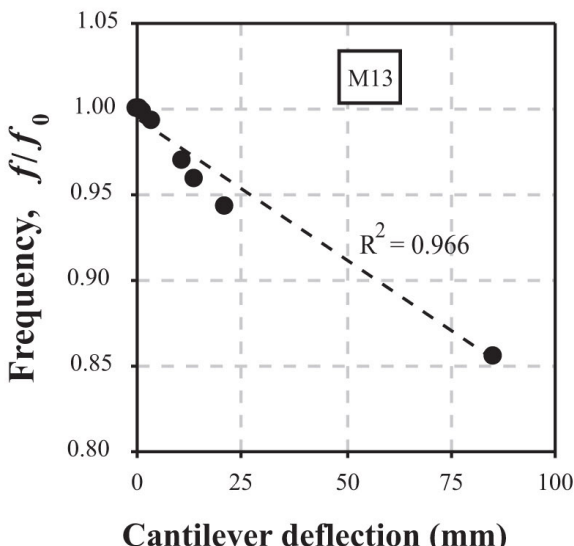

(b)

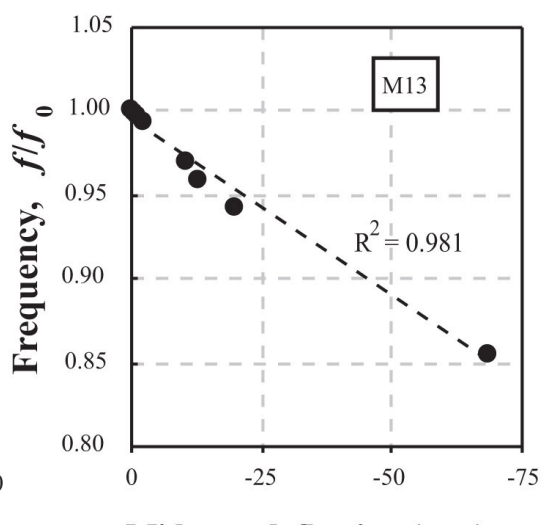

Midspan deflection (mm)

(c)

Figure 10. (a) Evolution of frequency M13 with load in test ST1, and (b)-(c) comparison of frequency change with evolution of deflections.

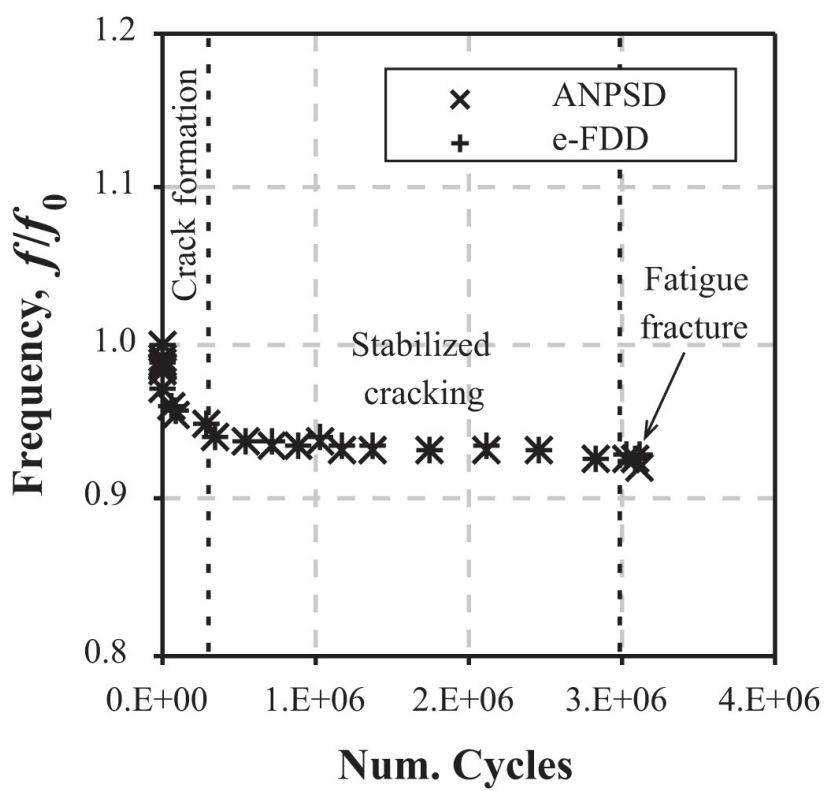

(a)

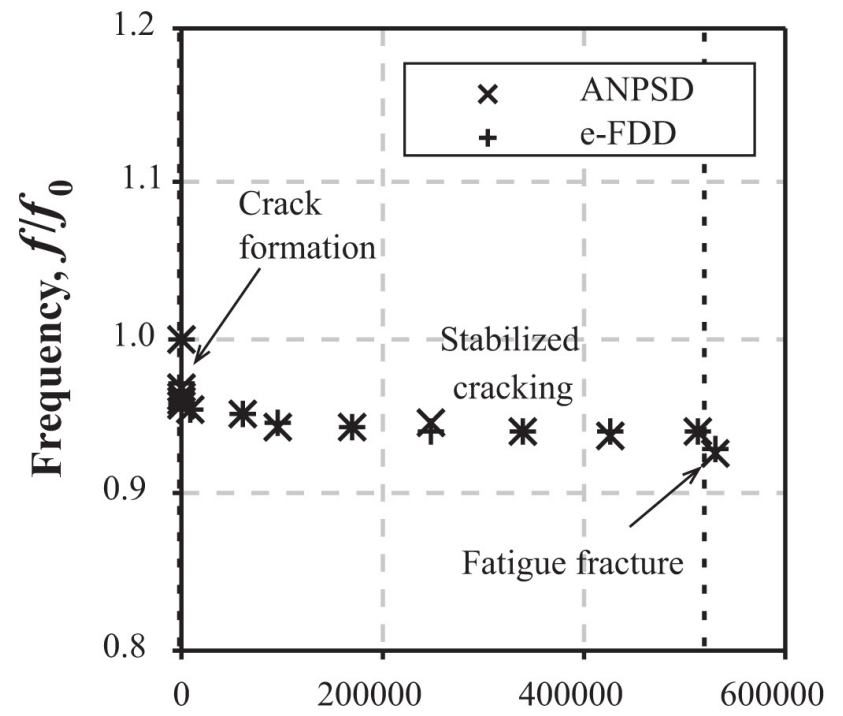

Num. Cycles 


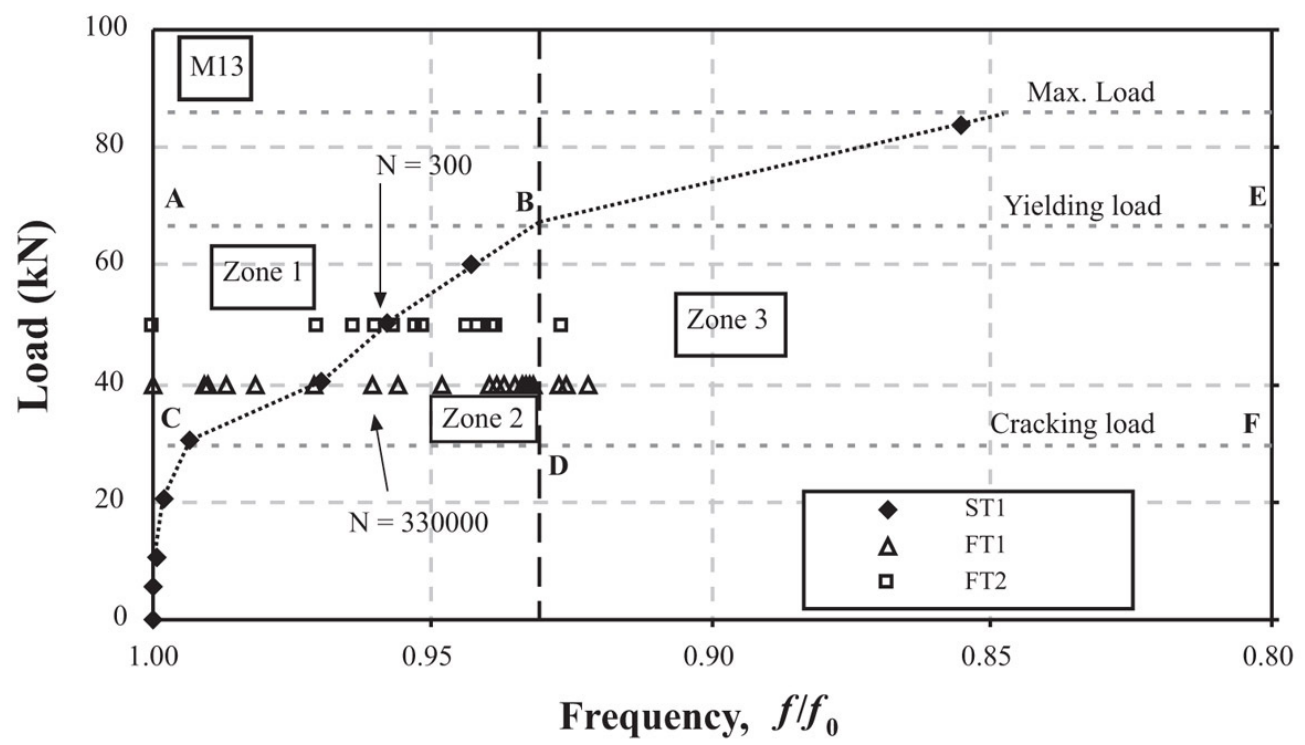

Figure 12. Evolution of frequency M13 with load cycles in fatigue tests: (a) Test FT1; (b) Test FT2.

to Figure 10(a)-. Three zones are considered in the graphic. The results of the crack formation stage for the fatigue tests lie in zone 1 (triangle $\mathrm{ABC}$ ), which locates at the left-hand side of the static curve BC. It can be observed that the end of the crack formation stage $(N=330000$ cycles for test FT 1 and $N$ $=300$ cycles for test FT2) fits very well with this curve. Zone 2 (triangle $\mathrm{BCD}$ ) is bounded by the static curve $\mathrm{BC}$ and the vertical line $\mathrm{BD}$ that corresponds to the yielding point of the static test $\left(f / f_{\mathrm{o}} \approx 0.93\right)$. This zone corresponds to the stabilized cracking stage in the fatigue tests. Furthermore, the points that represent the measurements taken after fatigue failure of the reinforcement in tests FT1 and FT2 fall into zone 3 at the right-hand side of line $\mathrm{BD}$. It is noted that the bars that remained intact after fatigue failure suddenly yielded due to the small reinforcement ratio of the specimens, which suggests that zone 3 corresponds to the stage of yielding of the reinforcement. From the analysis of Figure 11, it can be concluded that the frequency evolution of the static test is a good tool to establish the three stages developed in the fatigue tests and build the regions of the load-frequency diagram that correspond to them.

The employ of the evolution of damping ratio to follow the structural damage was more complicated than the use of natural frequencies due to the larger scatter obtained for this parameter. The identification of the experimental stages is not easy from the evolution of the damping ratio of modes M1M10. Better results were obtained for the high order modes (M11 and M13). The coefficient of determination between damping ratio change and deflections was smaller than the one obtained between natural frequencies and deflections. This is evident for the fatigue tests $\left(\mathrm{R}^{2}=0.58-0.74\right)$, while for the static case the correlation is still rather $\operatorname{good}\left(\mathrm{R}^{2}=0.94-\right.$ o.96). The scatter obtained for the damping values does not allow the use of the damping factors of the static test as a reference for the fatigue tests in a similar way to the ones obtained for the frequency in Figure 11.

\section{CONCLUSIONS}

This paper presents the results of an experimental campaign dealing with the correlation between change of dynamic properties and structural damage of reinforced concrete. The dynamic properties (natural frequencies, damping ratios and modal shapes) were obtained by means of output-only techniques from impact excitation vibration tests. The analysis has focused on the damage caused by fatigue loading on reinforced concrete specimens reproducing the top slab of concrete bridges, with a focus on the transverse behaviour. Three significant stages were developed in the tests: crack formation, stabilized cracking and fatigue fracture of the reinforcement. The results indicate that the change of natural frequencies is an excellent tool to follow the structural damage of the specimens due to the good correlation between the frequency decrease and the increase of deflections with load cycles. In addition, the study indicates that the results obtained in a static test provide a useful reference to establish criteria to identify the fatigue damage. The employ of the damping ratio has more difficulties to identify structural damage due to the more irregular evolution obtained for this parameter.

\section{ACKNOWLEDGEMENTS}

The financial support provided by the Spanish Ministry for Science and Innovation (projects PSE-370000-2009-10 and IPT-370000-2010-12) is gratefully acknowledged.

\section{REFERENCES}

(1) Cunha, A., Caetano, E. (2006): Experimental modal analysis of civil engineering structures. Sound and Vibration, (6): 12-20.

(2) Kim, B.H., Stubbs, N., Park, T. (2005). A new method to extract modal parameters using output-only responses. Journal of Sound and Vibration, 282(1-2): 215-230, doi: http://dx.doi.org/10.1016/j.jsv.2004.02.026.

(3) Gentile, C., Bernardini, G. (2008). Output-only modal identification of a reinforced concrete bridge from radar-based measurements. NDT\&E International, 41(7): 544-553, doi: http://dx.doi.org/10.1016/j.ndteint.2008.04.005. 
(4) Altunisik, A.C., Bayraktar, A., Sevim, B. (2011). Output-only system identification of posttensioned segmental concrete highway bridges. ASCE Journal Bridge Engineering, 16(2): 259-266, doi: http://dx.doi.org/10.1061/(ASCE)BE.19435592.0000150.

(5) González, M.N., Cobo, A., Fuente, J.V. (2013). Obtención de modelos de cálculo de sistemas provisionales de protección de borde mediante la técnica de Análisis Modal Operacional. Informes de la Construcción, 65(529): 99-106, doi: http:// dx.doi.org/10.3989/ic.11.133.

(6) Bairán, J.M., Marí, A.R., Mohr, S. (2010). Estudio del comportamiento del hormigón armado ante esfuerzos normales y tangentes mediante modelos seccionales de interacción completa. Informes de la Construcción, 62(518): 65-77, doi: http://dx.doi.org/10.3989/ic.09.021.

(7) Waltering, M., Bongard, V., Waldmann, D., Maas, S., Zürbes, A. (2009). Vergleich statischer und dynamischer Methoden zur Zustandsbewertung von Stahlbeton- und Spannbetontragwerken (Comparison of static and dynamic methods to assess the state of reinforced and prestressed concrete structures). Beton- und Stahlbetonbau, 104(10): 628-641, doi: http://dx.doi.org/10.1002/best.200900024.

(8) De Roeck, G., Peeters, B., Maeck, J. (2000). Dynamic monitoring of civil engineering structures. En Papadrakakis, M., Samartin, A., Onate, E. (Eds.), Computational methods for shell and spatial structures IASS-IACM 2Ooo (pp. 1-24). Athens, Greece: (C) ISASR-NTUA.

(9) Maya, L.F., Albajar, L., Portabella, J., Lópe,z C., Morán, F. (2010). Uso de hormigones con fibras de ultra-alta resistencia para el desarrollo de conexiones entre elementos prefabricados. Informes de la Construcción, 62(520): 27-41, doi: http://dx.doi.org/10.3989/ic.09.062.

(10) Casas, J.R., Aparicio, A.C. (1994). Structural damage identification from dynamic test data. ASCE Journal of Structural Engineering, 120(8): 2437-2450, doi: http://dx.doi.org/10.1061/(ASCE)o733-9445(1994)120:8(2437).

(11) Ndambi, J.M., Vantomme, J., Harri, K. (2002). Damage assessment in reinforced concrete beams using eigenfrequencies and mode shape derivatives. Engineering Structures, 24(4): 501-515, doi: http://dx.doi.org/10.1016/So1410296(01)00117-1.

(12) Schläfli, M., Brühwiler, E. (1998). Fatigue of existing reinforced concrete bridge deck slabs, Engineering Structures. Engineering Structures, 20(11): 991-998, doi: http://dx.doi.org/10.1016/So141-0296(97)00194-6.

(13) Newhook, J., Limaye, V. (2007). Monitoring fatigue life in concrete bridge deck slabs. En Proceedings of SPIE, $v$ 6531, Nondestructive characterization for composite materials, aerospace engineering, civil infrastructure, and homeland security (pp. R1-8).

(14) Sasaki, K.K., Paret, T., Araiza, J.C., Hals, P. (2010). Failure of concrete T-beam and box-girder highway bridges subjected to cyclic loading from traffic. Engineering Structures, 32(7): 1838-1845, doi: http://dx.doi.org/10.1016/j.engstruct.2010.01.006.

(15) Peeters, B., Maeck, J., De Roeck, G. (2000). Excitation sources and dynamic system identification in civil engineering. En European COST F3 Conference on System Identification and Structural Health Monitoring, (pp. 341-350). Madrid, Spain.

(16) Neild, S.A., Williams, M.S., McFadden, P.D. (2003). Nonlinear vibration characteristics of damaged concrete beams. ASCE Journal Structural Engineering, 129(2): 260-268, doi: http://dx.doi.org/10.1061/(ASCE)0733-9445(2003)129:2(260).

(17) Zanuy, C., Maya, L.F., Albajar, L., de la Fuente, P. (2011). Transverse fatigue behaviour of lightly reinforced concrete bridge decks. Engineering Structures, 33(10): 2839-2849, doi: http://dx.doi.org/10.1016/j.engstruct.2011.06.oo8.

(18) Manterola, J. (2002). Puentes, Tomos I-VI. Madrid, Spain: Colegio Ingenieros de Caminos, Canales y Puertos.

(19) Ministerio de Fomento. (2008). Instrucción de Hormigón Estructural EHE o8. Madrid, Spain. http://www.fomento. es/MFOM/LANG_CASTELLANO/ORGANOS_COLEGIADOS/CPH/instrucciones/EHEo8INGLES/.

(20) Cornelissen, H. A. (1984). Fatigue failure of concrete in tension, Heron, 29 (4), pp. 1-68.

(21) Gilbert, R.I. (2007). Tension stiffening in lightly reinforced concrete slabs. ASCE Journal of Structural Engineering, 133(6): 899-903, doi: http://dx.doi.org/10.1061/(ASCE)0733-9445(2007)133:6(899).

(22) Felber, A.J. (1993). Development of a hybrid bridge evaluation system (PhD Thesis), p. 277. Vancouver, Canada: University of New British Columbia.

(23) Felber, A., Cantieni, R. (1996). Advances in ambient vibration testing: Ganter bridge, Switzerland. Structural Engineering International, 6(3): 187-190, doi: http://dx.doi.org/10.2749/101686696780495671.

(24) Brincker, R., Ventura, C. E., Andersen, P. (2001). Damping estimation by frequency domain decomposition. En Proc. International Modal Analysis Conference IMAC, (pp. 1-6). Kissimee, Florida.

(25) ANSYS. (2010). ANSYS Mechanical APDL Programmer's Manual. Release 13.o. Canonsburg, PA: SAS IP, Inc.

$$
* * *
$$

